\title{
Chromato-panning: an efficient new mode of identifying suitable ligands from phage display libraries \\ Wim Noppe ${ }^{1}$, Fatima Plieva2,3, Igor Yu Galaev², Hans Pottel ${ }^{1}$, Hans Deckmyn ${ }^{1}$ and Bo Mattiasson*2
}

\author{
Address: ${ }^{1}$ Interdisciplinary Research Center, Katholieke Universiteit Leuven Campus Kortrijk, E Sabbelaan 53, B-8500 Kortrijk, Belgium, \\ 2Department of Biotechnology, Lund University, P. O. Box 124, SE-22100 Lund, Sweden and 3Protista Biotechnology AB, P.O. Box 86, SE-26722 \\ Lund, Sweden \\ Email: Wim Noppe -Wim.Noppe@kuleuven-kortrijk.be; Fatima Plieva - Fatima.Plieva@biotek.lu.se; Igor Yu Galaev - Igor.Galaev@biotek.lu.se; \\ Hans Pottel - hans.pottel@kuleuven-kortrijk.be; Hans Deckmyn - hans.deckmyn@kuleuven-kortrijk.be; \\ Bo Mattiasson* - Bo.Mattiasson@biotek.lu.se \\ * Corresponding author
}

Published: 17 March 2009

BMC Biotechnology 2009, 9:21 doi:|0.|| 86/|472-6750-9-2|
Received: 25 August 2008

Accepted: 17 March 2009

This article is available from: http://www.biomedcentral.com/1472-6750/9/2I

(C) 2009 Noppe et al; licensee BioMed Central Ltd.

This is an Open Access article distributed under the terms of the Creative Commons Attribution License (http://creativecommons.org/licenses/by/2.0), which permits unrestricted use, distribution, and reproduction in any medium, provided the original work is properly cited.

\begin{abstract}
Background: Phage Display technology is a well established technique for high throughput screening of affinity ligands. Here we describe a new compact chromato-panning procedure for selection of suitable binders from a phage peptide display library.

Results: Both phages and E. coli cells pass non-hindered through the interconnected pores of macroporous gel, so called cryogel. After coupling a ligand to a monolithic cryogel column, the phage library was applied on the column and non-bound phages were washed out. The selection of strong phage-binders was achieved already after the first panning cycle due to the efficient separation of phage-binders from phage-non-binders in chromatographic mode rather than in batch mode as in traditional biopanning procedures. E. coli cells were applied on the column for infection with the specifically bound phages.
\end{abstract}

Conclusion: Chromato-panning allows combining several steps of the panning procedure resulting in 4-8 fold decrease of total time needed for phage selection.

\section{Background}

Since the introduction of the phage display peptide libraries in 1985 [1], when a vector could directly display a small foreign peptide in one of the coating proteins of the filamentous M13 phage particle, the greatest task has been to find suitable ligands. Because of the need for repeated panning rounds to isolate high-affinity ligands, the whole panning procedure is rather laborious and time consuming. Therefore, a shorter, more efficient procedure, with fewer steps and fewer panning cycles would be desirable.
Phage display is suitable not only for peptides, but also for small proteins and protein fragments (e.g. antibody fragments), which can be expressed on the phage surface proteins [2]. Several linear [3-6] and constrained cyclic [7-10] phage peptide libraries have been sucessfully used to screen for affinity ligands against a variety of targets, all of which were based on use of the laborious, repetitive biopanning procedure. The technique of phage display and its applications is more extensively discussed in some recent review papers. C. Adda et al. [2] and J. Kehoe et 
al.[11] review the technique of phage display in all its aspects. M. Paschke [12]; M. Szardenings [13]; M. Arap [14]; C. Mersich et al. [15] and V. Petrenko [16] present extensive reviews on the present state and applications of the phage display technology.

To separate phages binding to the ligand from non-binders, the ligand is immobilized on a solid carrier allowing for easy separation of the liquid phase, which contains predominantly non-binding phages, from the solid phase, which contains mainly binding phages (Figure 1a). Many variations of the technique have been described, however, rigid plastic materials, such as polystyrene, have traditionally been used as carriers to provide a nonporous interface for ligand immobilization. As the diffusivity of phages is negligible due to their size, the ligands immobilized in diffusional pores will be essentially unavailable to the phages. To provide a larger interface area, the size of
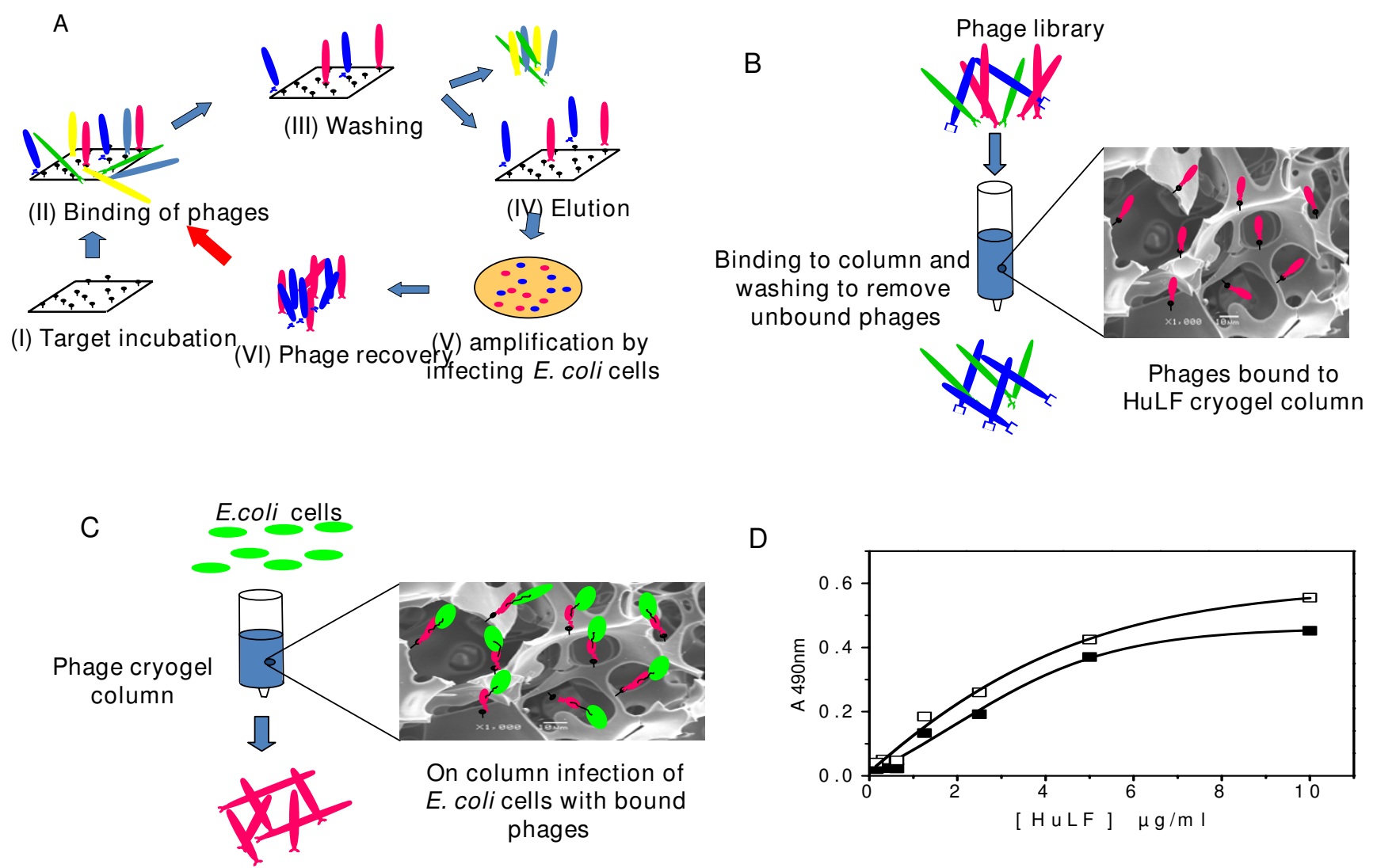

Figure I

Panning procedures. (a) Schematic representation of a traditional biopanning procedure. After target incubation (I) and postcoating, a phage library is added and incubated (II). In a washing step (III) non-bound phages are washed away followed by an elution step (IV). The $E$. coli cells are consequently infected with the eluted phages (V) and out-plated on agar plates for amplification. After overnight grow the cells are harvested and the phages revovered by a precipitation step (VI). These phages are used for subsequent panning rounds until high affinity phages are obtained. Schematic representation of the Chromato-panning procedure: (b) On-column panning. A cryogel column with the target protein covalently coupled, is washed with PBS buffer followed by loading of a sample of the phage library at $0,5 \mathrm{ml} . \mathrm{min}^{-1}$. After washing out the non-bound phages, the bound phages can be eluted with I $\mathrm{M} \mathrm{NaCl}$ and further used for infection of $E$. coli cells as described for a classical panning procedure. (c) On-column infection. After the on-column panning as in (b), without elution of bound phages, the column is incubated at $37^{\circ} \mathrm{C}$ and one column volume of $E$. coli cells is applied on the column, followed by an incubation time (no flow) for 45 min. Next, the infected $E$. coli cells are eluted and out-plated on agar plates. After overnight grow, the cells are harvested and the phages recovered by a precipitation step. (d) Evaluation of the elution solvent in biopanning. Two similar chromato-panning procedures were performed with a linear hexamer peptide library using a different elution solvent. The bound phages were eluted from the column using either $0.1 \mathrm{M}$ glycine, $\mathrm{pH} 2.2$ (open square) or I $\mathrm{M} \mathrm{NaCl}$ (black square) as elution solvent. The eluted phages were used to infect $E$. coli cells. After amplification and harvesting, the binding affinity of the harvested phages was analyzed using phage ELISA as described in Materials and Methods. 
the carrier beads can be decreased or the surface can be decorated with tentacles. However, this does not circumvent the main shortcoming of the traditional biopanning process, namely that washing is carried out in batch mode which is a "one-plate" operation and hence rather inefficient from a bioseparation point of view. Not surprisingly, several repetitive rounds (i.e. a few "one-plate" operations) are needed to isolate strong binders. The separation of a liquid phase from a solid phase in chromatographic mode (multi-plate operation) could be assumed to be much more efficient, giving efficient separation of binders from non-binders in a single operation. To determine whether this is in fact the case, an affinity chromatographic material that combines several non-trivial characteristics is needed. Such a material should:

(i) be macroporous, with a pore size no less than $10 \mu \mathrm{m}$, as the phages themselves are about $1 \mu \mathrm{m}$ long (larger pore sizes, up to $100 \mu \mathrm{m}$, are desirable to allow the possibility of direct infection of the cells by the phages bound to the affinity matrix);

(ii) have highly interconnected pores, allowing convectional rather than diffusional mass transport of phages and presumably cells inside the pores;

(iii) be hydrophilic with minimal non-specific binding of phages or cells and hence no need for post-coating;

(iv) contain active groups for the immobilization of the ligand.

We have recently presented a material with the required combination of properties for chromatographic separation of microbial and mammalian cells [17-20]. Macroporous hydrogels, or cryogels, are produced using polymerization in semi-frozen conditions, where ice crystals perform the role of the porogen, and polymerization proceeds in the non-frozen liquid phase [21]. The properties of cryogels and the architecture of interconnected macropores are presented in detail in recent publications by Plieva et al. [22-24]. In this communication we present a new chromato-panning procedure based on using a cryogel as a matrix for ligand immobilization.

\section{Results and discussion On-column panning}

The efficiency of the column panning procedure (Figure 1b) was studied by comparing the performance of the chromato-panning procedure with that of the tube panning procedure. Different phage libraries were used, and three panning rounds were performed. Human lactoferrin (HuLF) was used as the ligand, and this was coupled to the column as described in Materials and Methods. The most frequently used elution media in biopanning proce- dures are glycine and hydrochloric acid at a $\mathrm{pH}$ of $\sim 2.2$. Frequent use of these acidic buffers may denature the bound ligand, leading to a loss in binding capacity. In earlier work $[25,26] 1 \mathrm{M} \mathrm{NaCl}$ was used as elution medium to elute protein from a cryogel-phage column with good results. To evaluate the elution strength both elution media were investigated in a column panning procedure, showing similar elution efficiencies (Figure 1d). Based on these findings both elution solvents were used in further experiments: (i) for the tube panning procedure, $0.1 \mathrm{M}$ glycine, $\mathrm{pH}$ 2.2, was used as the elution medium and (ii) for the column panning procedure $1 \mathrm{M} \mathrm{NaCl}$ was used as elution medium. After elution, phages from each panning round were amplified and recovered, their binding efficiencies were tested using a phage ELISA as described in Materials and Methods. Different phage libraries, a cyclic hexamer (C6), linear hexamer (L6) and a linear pentadecamer (L15) library, were used for biopanning. After one round in the column panning procedure, the selected phages show comparable (C6 library) or somewhat higher (L15 library) binding strength towards HuLF as compared to the phages obtained after the third panning round in the tube panning experiment (Figure 2a, b). The L6 library showed similar results to the C6 library (data not shown). In the tube panning experiment an increase in binding strength was observed in consecutive panning rounds $(\mathrm{R} 3>\mathrm{R} 2>\mathrm{R} 1)$. In the column panning procedure, no further increase was observed after the first round (L6 and C6 library). Table 1 . shows that a statistical significant difference ( $p<0.05$ ) between top-values (plateau levels) is observed for all three used between the first round of the tube panning and the chromato-panning procedure, which disappeared after the third tube panning round. Furthermore, also a paired comparison over the three libraries between the first round of the tube panning and

Table I: Statistical analysis data

\begin{tabular}{|c|c|c|c|c|c|}
\hline Library & Id & Panning round & Top-value & $95 \% \mathrm{Cl}$ & $R^{2}$ \\
\hline \multirow[t]{3}{*}{$\mathrm{C} 6$} & $\mathrm{a}$ & Trl & 0.853 & {$[0.712-0.994]^{\mathrm{bc}}$} & 0.979 \\
\hline & b & $\mathrm{Tr} 3$ & 1.622 & {$[1.382-1.862]^{\mathrm{a}}$} & 0.978 \\
\hline & c & $\mathrm{Crl}$ & 1.605 & {$[1.370-1.839]^{\mathrm{a}}$} & 0.981 \\
\hline \multirow[t]{3}{*}{ L6 } & $\mathrm{a}$ & $\mathrm{Trl}$ & 0.697 & {$[0.600-0.794]^{\mathrm{bc}}$} & 0.990 \\
\hline & b & Tr3 & 1.640 & {$[1.500-1.780]^{\mathrm{a}}$} & 0.990 \\
\hline & c & $\mathrm{Crl}$ & 1.545 & {$[1.299-1.790]^{\mathrm{a}}$} & 0.962 \\
\hline \multirow[t]{3}{*}{ LI5 } & $\mathrm{a}$ & Trl & 1.354 & {$[1.279-1.430]^{\mathrm{c}}$} & 0.999 \\
\hline & $b$ & $\mathrm{Tr} 3$ & 1.382 & {$[1.180-1.584]^{c}$} & 0.986 \\
\hline & c & $\mathrm{Crl}$ & 1.832 & {$[1.645-2.020]^{\mathrm{ab}}$} & 0.994 \\
\hline
\end{tabular}

For the three phage libraries C6, L6 and LI 5, top-values, $95 \% \mathrm{Cl}$ and $\mathrm{R}^{2}$ (see Material and Methods) was calculated and compared for the tube panning round I, $3(\mathrm{Trl}, \mathrm{Tr} 3)$ and chromato-panning procedure round $3(\mathrm{Crl})$. Superscripts denote statistical significant difference ( $P$ $<0.05$ ) between top-values (e.g. top "a" is statistically significant different from tops " $b$ " and "c"). 
A

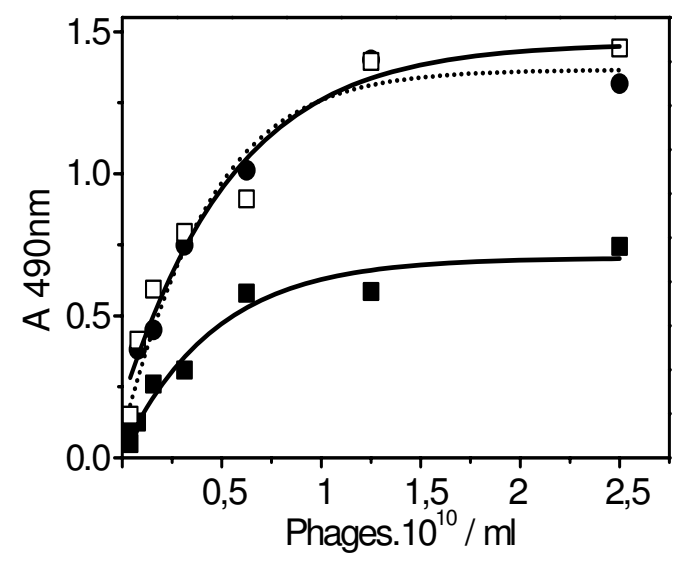

B

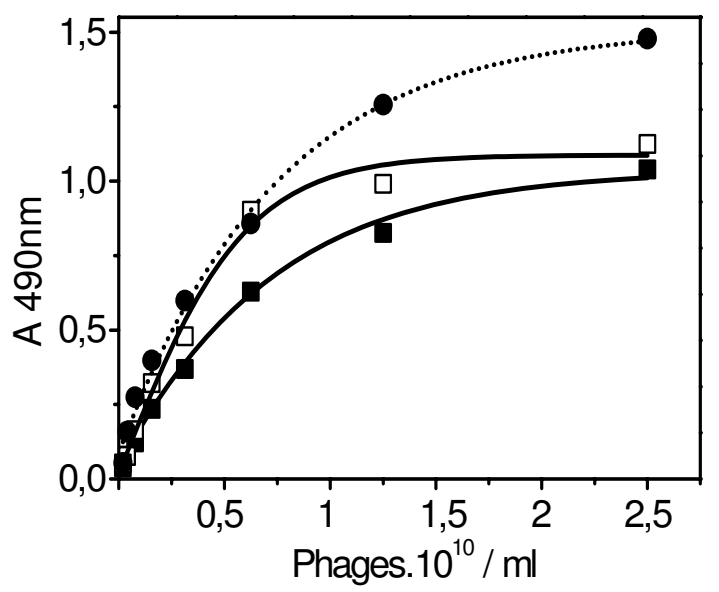

Figure 2

Efficiency of the panning procedures. Different phage libraries, C6 and LI5, were used in both a tube biopanning and a chromato-panning procedure. In both procedures three rounds were performed as described in Table I. The binding efficiency of the obtained phages was determined using HuLF ELISA as described in Materials and Methods. (a) Biopanning with a C6 library. Tube panning: Round I (black square) Round 3 (open square); column panning: Round I (black circle-dotted line). (b) Biopanning with a LI 5 library. Tube panning: Round I (black square) and Round 3 (open square); column panning: Round I (black circle-dotted line).

the chromato-panning procedure resulted in a statistically significant difference $(\mathrm{p}=0.025)$. These results show the superiority of the chromato-panning procedure for fast screening for high affinity ligands.

\section{On-column infection}

To further optimize the column panning procedure, oncolumn infection of $E$. coli cells was investigated. The macropores in the cryogel are large enough to allow E. coli
A
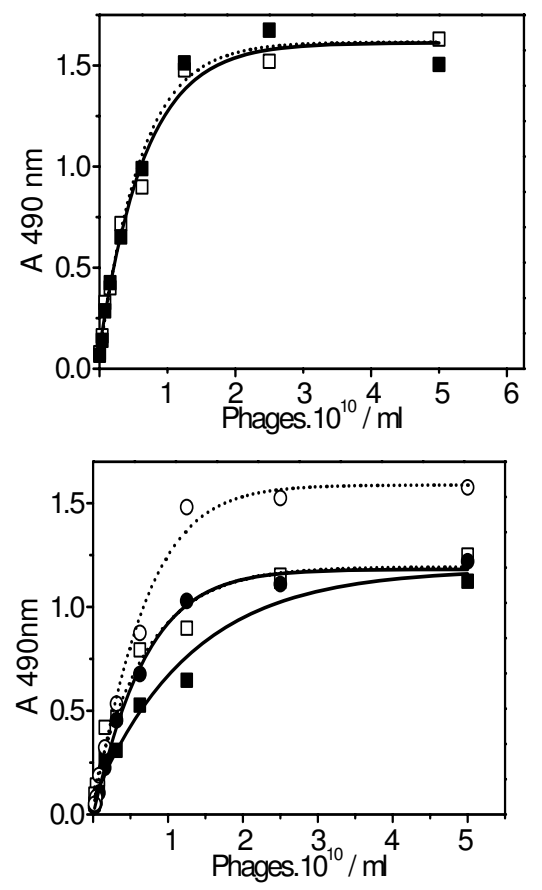

C

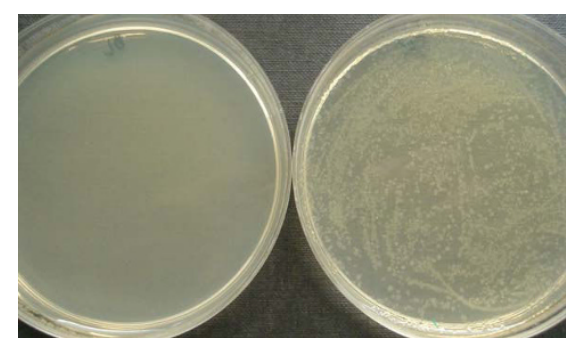

Figure 3

On-column E. coli infection. Two phage libraries, L6 and LI5, were used for column panning and on-column infection. Two rounds were performed as described in Table I. As a reference sample, a single phage clone $\mathrm{HuN}$, was used for on-column infection. The binding efficiency was determined using HuLF ELISA as described in Material and Methods. (a) On-column cell infection on a HuLF column with the HuN single-phage clone. HuN phage reference sample (no infection performed) (black square) and $\mathrm{HuN}$ fraction eluted with I $\mathrm{M} \mathrm{NaCl}$ after on-column infection (open square-dotted line). (b) Column panning and on-column cell infection on the HuLF column with the L6 and LI 5 phage peptide libraries. Two panning rounds were performed. Phages from the L6 phage peptide library (solid lines): Round I (black square) and Round 2 (open square); phages from the LI 5 phage peptide library (dotted lines): Round I (black circle) and Round 2 (open circle O). (c) Control of cell growth on agar plates after on-column phage infection. (left): $E$. coli cells which were not infected with phages were plated on agar plates containing tetracycline and incubated overnight at $37^{\circ} \mathrm{C}$. (right): E. coli cells were applied to the HuLF column on which phages were bound after a panning round. After cell infection and elution, the I $\mathrm{M} \mathrm{NaCl}$ fraction was plated on agar plates containing tetracycline and grown overnight at $37^{\circ} \mathrm{C}$. 
Table 2: Comparative time frame of chromato-panning protocol and tube panning protocol

\begin{tabular}{|c|c|c|c|}
\hline Chromato-panning & & Tube panning & \\
\hline Round I (h) & & Round I (h) & \\
\hline \multirow[t]{2}{*}{ Column equilibration } & 0.25 & Target coating & 18 \\
\hline & & Wash-postcoat & 2.25 \\
\hline \multirow[t]{2}{*}{ On column panning } & 1 & Phage incubation & 20 \\
\hline & & Washing/elution & 0.50 \\
\hline On column infection & 0.50 & Infection & 0.50 \\
\hline Elution & 0.25 & & \\
\hline Plating/amplification & 18 & Plating/amplification & 18 \\
\hline Phage recovery & 3 & Phage recovery & 3 \\
\hline Time & $\sim 23 \mathrm{~h}$ & & $\sim 62 \mathrm{~h}$ \\
\hline No additional panning rounds are needed & & $\begin{array}{l}2 \text { additional panning rounds are performed } \\
\text { Phage incubation } R 2 / 3\end{array}$ & 2.50 \\
\hline TOTAL TIME & $\sim 23 \mathrm{~h}$ & & $\sim 152 \mathrm{~h}$ \\
\hline
\end{tabular}

A mean time frame of each step in the panning procedure is presented for one panning round. The total time represents the time frame for a complete panning procedure as described in Methods.

cells to pass freely through the plain cryogel without blocking the pores [26]. However, on the HuLF cryogel we observed binding of cells that could be eluted from the cryogel with $\mathrm{NaCl}$, in accordance with previous observations that $E$. coli cells bound to an anion-exchange cryogel column were eluted by $\mathrm{NaCl}[27]$. As HuLF is positively charged at $\mathrm{pH} \sim 7.0$, the HuLF-cryogel may act as an "anion-exchanger", which could explain our observation. $\mathrm{NaCl}(1 \mathrm{M})$ eluted all cells from the column. By immediately diluting the $1 \mathrm{M} \mathrm{NaCl}$ eluate in Luria broth (LB) medium, the final $\mathrm{NaCl}$ concentration of the eluted cell suspension was reduced to approx. $0.4 \mathrm{M} \mathrm{NaCl}$. This $\mathrm{NaCl}$ concentration had no negative effect on the viability of the cells. Under these conditions we observed a similar growth rate on agar plates to that of cells that had not come into contact with high salt concentrations.

The on-column infection procedure was first tested with a single-clone phage (HuN phage clone) as described in Materials and Methods. The amount of amplified phages after on-column infection was comparable to the amount obtained in a tube panning procedure or a column panning procedure with a separate infection step. The binding strength of the phages obtained was similar to that for phages obtained from a normal panning procedure (Figure 3a). A similar result was obtained with phage clones Hu14 and Hu5 (data not shown) although the three phage clones expressed a different peptide sequence on the PIII protein [7]. The same procedure was consequently performed with the L6 and L15 phage libraries. Two column panning rounds and on-column infection were performed with each phage library. The amount of phages and the binding strength were determined after each panning round. Again, the amount of phages was comparable to the amount of phages obtained in the other panning procedures. The binding strength was also similar as that obtained in the column panning procedure with a separate infection step. Again, the results show that only one panning round is necessary to obtain specific phages for the L6 library. Statistical analysis shows no significant difference between the topvalues of round 1 and 2 of the chromato-panning (95\% CI round 1: 1.069-1.432; 95\% CI round 2: 1.199-1.393). For the L15 library still some increase is observed after the second round (95\% CI round 1: 1.295-1.550; 95\% CI round 2: 1.627-2.176), probably due to the higher diversity of phages present in the library (Figure $3 \mathrm{~b}$ ), indicating that a second panning round might here be advisable. These results are in agreement with those shown in Figure $2 b$, where a similar column panning procedure was performed except that the infection step was performed separately and not on-column. These results confirm that biopanning was achieved on the HuLF column, and that on-column infection of the E. coli cells took place.

To further confirm the on-column infection of the E. coli cells we measured the amplification rate of the E. coli cells after infection on the column. E. coli cells that were not in contact with phages (blank sample) did not grow on agar plates containing tetracycline. E. coli cells that were infected by phages on the column survived and grew on the agar plates containing tetracycline (Figure 3c). After the cells were infected and eluted from the column, the cell suspension was centrifuged and the pellet re-suspended in LB buffer. At this point, the optical density at 
$600 \mathrm{~nm}\left(\mathrm{OD}^{600}\right)$ was measured. After plating, overnight incubation at $37^{\circ} \mathrm{C}$ and harvesting the cells in $\mathrm{LB}$ medium, $\mathrm{OD}^{600} \mathrm{~nm}$ was measured again. A 950 fold increase in $\mathrm{OD}^{600}$ was observed, which indicates that the cells were effectively infected on the HuLF cryogel column. The new panning procedure is independent of the ligand or phage library used. We used different phage peptide libraries and two different proteins as the ligand. The results presented above are based on results obtained with HuLF as ligand. Similar results were obtained in an experiment with $\alpha$-chymotrypsin as the ligand and the L6 phage peptide library (data not shown).

\section{Chromato-panning procedure}

To evaluate the chromato-panning procedure it was compared with the traditional biopanning procedure (Table 2 ) as well with other protocols (Table 3 ) described in the literature [28-30]. Special attention was paid to the total time required for the procedure, the efficiency of the elution media, and the efficiency of the procedure in terms of the number of rounds necessary to obtain high-affinity binders.

The total time is considerably shorter when using a column procedure (Table 2 ). Advantages of the column procedure are: no target coating is needed for each round as the column is re-usable, no post-coating is needed, the contact time between the phage-containing solution and the column is shorter and, finally, a milder elution medium can be used. The first column panning round takes about $1 / 3$ of the time required for the first round in a tube panning procedure. If three rounds were needed a reduction of approximately $50 \%$ in time is obtained. Only 1 round was necessary to obtain high-affinity binders in the column panning procedure, compared to 3 rounds in the tube panning procedure. In this case column panning takes only approximately $1 / 6$ of the time needed for a tube panning.

\section{Conclusion}

The use of macroporous cryogels in a chromato-panning procedure has various advantages. The large interconnecting pores of the cryogel allow (i) free passage of bacteriophages during the panning step without clogging the column, and (ii) free passage of E. coli cells so that infection can take place on-column. (iii) A significant time saving can be achieved as only one column panning round is needed to select high-affinity phage clones. (iv) A milder elution solvent can be used to elute phages and E. coli cells, without denaturing the bound ligand on the column or having negative effects on the viability of the cells. At present we provided "proof-of-principle", it is clear that our procedure as well as the data need to be more extensively validated in the future before the method can be broadly used as an alternative for the classical biopanning and as a new platform for rapid screening of ligands.

\section{Methods}

\section{Preparation of cryogel monoliths}

The epoxy-activated macroporous cryogels were produced and provided by Protista Biotechnology AB (Lund, Sweden) according to published protocols [17].

\section{Tube biopanning procedure}

A solution of human lactoferrin (HuLF) at $10 \mu \mathrm{g} / \mathrm{ml}$ in phosphate-buffered saline (PBS) was coated for 2 hours at room temperature (RT) on sterile Nunc immunotubes (Nunc A/S) placed on a test-tube rotator at $10 \mathrm{rpm}$, fol-

Table 3: Comparative time frames of reported panning protocols

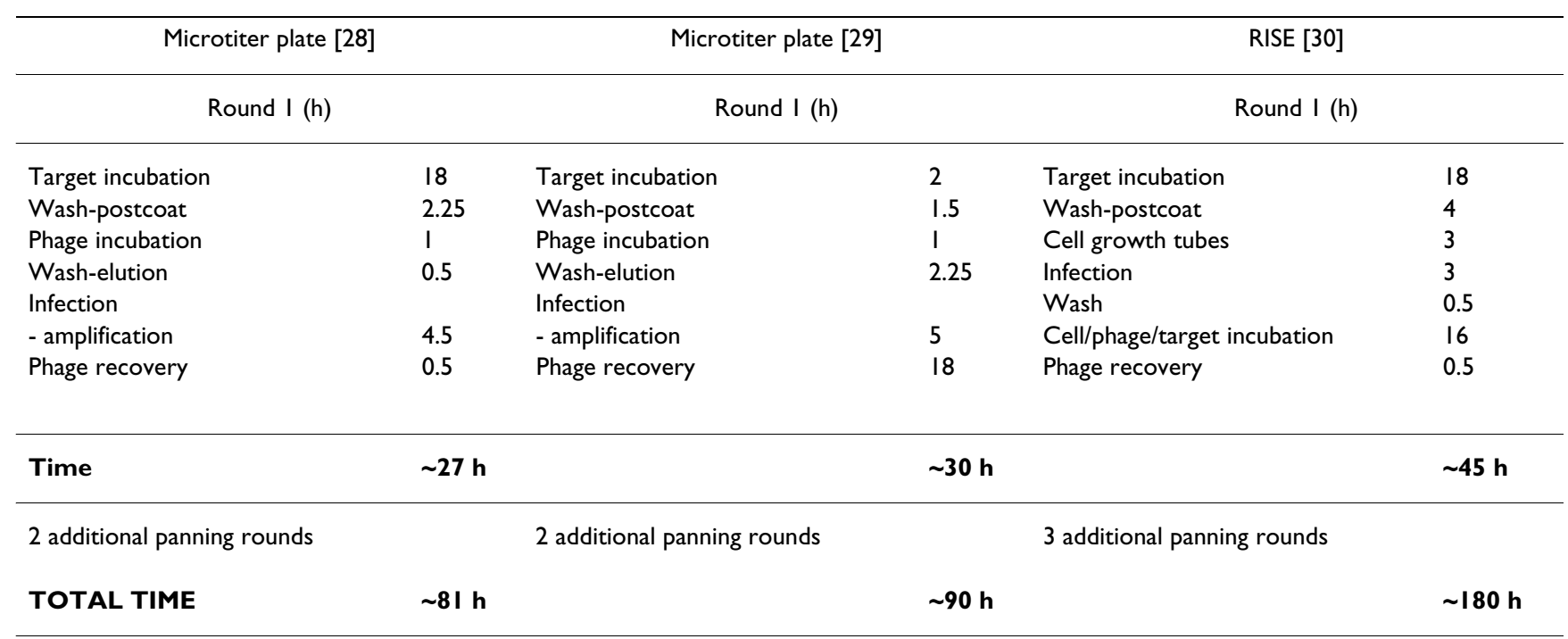

A mean time frame of each step in the panning procedure is presented for one panning round. The total time represents the time frame for a complete panning procedure as reported in the literature. 
lowed by standing incubation overnight at $4^{\circ} \mathrm{C}$. (Figure 1a). After discarding the coating solution the tubes were washed with PBS containing 0.2\% Tween-20 (TPBS). Post-coating was performed with a $4 \%(\mathrm{wt} / \mathrm{vol})$ solution of milk powder in PBS for at least 2 hours at RT. After washing with TPBS, $2 \times 10^{12}$ phages from a phage-display peptide library were added in PBS to the tube and incubated overnight at $4{ }^{\circ} \mathrm{C}$ on a test-tube rotator at $10 \mathrm{rpm}$. After careful washing with TPBS, the bound phages were eluted with $0.1 \mathrm{M}$ glycine, $\mathrm{pH} 2.0$, on a test-tube rotator for $15 \mathrm{~min}$ at RT. The eluate was neutralized by adding 1 $\mathrm{M}$ Tris pH 8.0 and kept on ice until infection. An overnight $E$. coli TG-1 (Stratagene) cell culture was diluted 100 times and grown at $37^{\circ} \mathrm{C}$ on a shaker until the $\mathrm{OD}^{600}$ was $\sim 0.500$. To $650 \mu$ leluted phages, $10 \mathrm{ml}$ of the E. coli TG-1 cell culture was added and incubated at $37^{\circ} \mathrm{C}$ for phage infection. After incubation, the cell suspension was centrifuged and the cell pellet was re-suspended in sterile Luria broth (LB) medium (Invitrogen). The cell suspension was subsequently plated on Luria agar plates containing 20 $\mu \mathrm{g} / \mathrm{ml}$ tetracycline-hydrochloride, and incubated overnight at $37^{\circ} \mathrm{C}$.

The cells were recovered in sterile LB medium and the cell suspension was centrifuged for $20 \mathrm{~min}$ at $7600 \times \mathrm{g}$ at $4^{\circ} \mathrm{C}$. To the clear supernatant, $1 / 3$ to $1 / 5$ volume of $20 \%$ PEG$6000 / 2.5 \mathrm{M} \mathrm{NaCl}$ was added, mixed and incubated on ice for $90 \mathrm{~min}$ for phage precipitation. Phages were recovered by centrifugation at $2000 \times \mathrm{g}$ for $20 \mathrm{~min}$. The pellet was resuspended in sterile distilled water and precipitated again with the PEG/NaCl solution. After incubation and centrifugation the phage pellet was finally re-suspended in PBS. The phage concentration was measured as the absorbance at $260 \mathrm{~nm}\left(\mathrm{~A}^{260}\right)\left(1 \mathrm{~A}\right.$ unit $=2.2 \times 10^{11}$ phages. $\left.\mathrm{ml}^{-1}\right)$.

In order to obtain phages specific to the ligand, three panning rounds were performed. In the consecutive panning rounds, $1 \times 10^{11}$ phages of the previous panning round was used for incubation in the coated immunotube. The incubation time was reduced to $90 \mathrm{~min}$ on a test-tube rotator followed by standing incubation for $60 \mathrm{~min}$. All ensuing steps were similar to those described for the first panning round. Finally, the phages were stored in PBS buffer $-5 \%(\mathrm{wt} / \mathrm{vol})$ glycerol at $-20^{\circ} \mathrm{C}$ until further use. All buffers were filtered through a $0.22 \mu \mathrm{m}$ filter and autoclaved before use.

\section{Ligand coupling to the monolithic cryogel}

Two dried epoxy-activated monolithic cryogels were inserted, one on top of the other, in a chromatographic column. The monolithic cryogels were swollen in sterile water and the upper adaptor was lowered onto the gel surface ( $9 \mathrm{ml}$ bed volume). The column was washed with sterile water and equilibrated with $0.1 \mathrm{M}$ carbonate buffer, $\mathrm{pH} 9.5$, at a flow rate of $1 \mathrm{ml} / \mathrm{min}$. A solution of HuLF in
$0.1 \mathrm{M}$ carbonate buffer, $\mathrm{pH}$ 9.5, was re-circulated over the column for 16 hours at a flow rate of $0.5 \mathrm{ml} / \mathrm{min}$ at $4{ }^{\circ} \mathrm{C}$. After coupling, the column was washed with $0.1 \mathrm{M}$ carbonate buffer, pH 9.5, until all non-bound HuLF had been removed, followed by re-circulation of $25 \mathrm{ml} 0.1 \mathrm{M}$ ethanolamine in $0.1 \mathrm{M}$ carbonate buffer, $\mathrm{pH} 9.5$, for 3 hours at a flow rate of $1 \mathrm{ml} / \mathrm{min}$ to block the remaining active epoxy groups. Finally, the column was washed with sterile water and PBS, and stored at $4{ }^{\circ} \mathrm{C}$ until further use.

\section{Chromato-panning}

The HuLF-cryogel column (Figure 1b) was washed with sterile PBS. Two $\mathrm{ml}$ of solution containing $1 \times 10^{12}$ phages of a phage-displayed peptide library was loaded onto the column at $0.5 \mathrm{ml} \cdot \mathrm{min}^{-1}$, followed by washing with $30 \mathrm{ml}$ PBS to remove unbound phages. The bound phage fraction was eluted, $1 \mathrm{ml}$ fractions were collected and stored at $20^{\circ} \mathrm{C}$ until further use. Two different elution media were investigated: $0.1 \mathrm{M}$ glycine, $\mathrm{pH} 2.0$ (used in the tube panning procedure), and $1 \mathrm{M} \mathrm{NaCl}$. After elution the column was washed with $2 \mathrm{M} \mathrm{NaCl}$ and re-equilibrated with PBS buffer. The eluted phages were amplified by infecting E. coli TG-1 cells as described above. Three panning rounds were performed using the same HuLF cryogel column.

\section{On-column cell infection}

The chromato-panning procedure was very similar to that described above. Instead of eluting the phages from the column, E. coli TG-1 cells were loaded onto the column for infection and phage amplification (Figure 1c). The phage-displayed peptide library was loaded onto the column, which was then washed with PBS to remove unbound phages. The column was then incubated at $37^{\circ} \mathrm{C}$. An overnight E. coli TG-1 cell culture was diluted 100 times and grown at $37^{\circ} \mathrm{C}$ on a shaker until $\mathrm{OD}^{600}$ reached $\sim 0.5$. One column volume, approx. $8-9 \mathrm{ml}$ cell suspension, was loaded onto the column and the flow was stopped. The cells were incubated on the column for 30 $\min$ at $37^{\circ} \mathrm{C}$. The cells were then eluted from the column by washing with $20 \mathrm{ml} \mathrm{LB}$ medium containing $1 \mathrm{M} \mathrm{NaCl}$. The eluate was collected in $20 \mathrm{ml} \mathrm{LB}$ medium to dilute the $\mathrm{NaCl}$ in order to maintain the viability of the E. coli cells. The cell suspension was immediately centrifuged at $750 \times$ $\mathrm{g}$ for $10 \mathrm{~min}$. The pellet was re-suspended in LB medium and plated on Luria agar plates containing $20 \mu \mathrm{g} / \mathrm{ml}$ tetracycline-hydrochloride, and incubated overnight at $37^{\circ} \mathrm{C}$. Phage recovery was similar to that described above. A second round of chromato-panning and on-column infection was performed in a similar way. In the second round the phage concentration was reduced to $5 \times 10^{10}$ phages. $\mathrm{ml}^{-1}$ ( $2 \mathrm{ml}$ applied to the column). All buffers used had been filtered through a $0.22 \mu \mathrm{m}$ filter and autoclaved. All procedures were performed at room temperature, except for the on-column infection and cell/phage elution which were performed at $37^{\circ} \mathrm{C}$. 


\section{Human lactoferrin ELISA}

The wells of a Microlon ELISA plate (Greiner Bio-One) were coated with $10 \mu \mathrm{g} / \mathrm{ml}$ of HuLF in PBS buffer and left overnight at $4^{\circ} \mathrm{C}$. After washing with TPBS, the wells were post-coated with a $4 \%$ (wt/vol) solution of milk powder in PBS for at least 2 hours at RT. After washing, a 2-fold serial dilution of phages starting at $1 \times 10^{11}$ phages $/ \mathrm{ml}$ in $0.4 \%$ (wt/vol) milk powder in PBS was added to the wells and incubated for 2 hours at RT. After extensive washing with TPBS, HRP/anti-M13 monoclonal conjugate (GE Healthcare) (1:2500 in $0.4 \%$ (wt/vol) milk powder in PBS) was added and incubated for 1 hour at RT. After extensive washing, $o$-phenylenediamine hydrochloride and hydrogen peroxide solution was added. The reaction was stopped by adding $4 \mathrm{M}$ sulfuric acid and the absorbance was measured at $490 \mathrm{~nm}$ using a BIO-Tek ELISA reader.

\section{Phage ELISA}

The wells of a Microlon ELISA plate were coated with 100 $\mu \mathrm{l}$ of $5 \times 10^{10}$ phages. $\mathrm{ml}^{-1}$ in PBS buffer overnight at $4^{\circ} \mathrm{C}$. After washing with TPBS, the wells were post-coated with a 4\% (wt/vol) solution of milk powder in PBS for at least 2 hours at RT. After washing, a 2-fold serial dilution HuLF at $10 \mu \mathrm{g} / \mathrm{ml}$ in $0.4 \%$ (wt/vol) milk powder in PBS was added to the wells and incubated for 2 hours at RT. After extensive washing with TPBS, HRP/Goat anti-HuLF conjugate (Nordic) (1:5000 in $0.4 \%$ (wt/vol) milk powder in PBS) was added and incubated for 1 hour at RT. After extensive washing, $o$-phenylenediamine hydrochloride and hydrogen peroxide solution was added. The reaction was stopped by adding $4 \mathrm{M}$ sulfuric acid and the absorbance was measured at $490 \mathrm{~nm}$ using a BIO-Tek ELISA reader

\section{Statistical analysis}

The data (absorbance versus phages) for the three libraries (C6, L6 and L15) were fitted with a simple sigmoidal dose-response model, starting from $\mathrm{Abs}=0$ and ending at Abs $=$ Top: Abs $=$ Top $/[1+10(\operatorname{logEC} 50-\mathrm{X})]$, with $\mathrm{X}$ the logtransformed concentration of phages/ml (GraphPad Prism 5.0). The fit parameter logEC50 corresponds to the concentration of phages at half the saturation level. The fit parameter Top, along with its 95\% Confidence Interval (CI), is used to represent the saturation level of the measured absorbance (for $\mathrm{X} \rightarrow \infty$ ). Statistical difference between saturation levels for tube panning after round 1 (R1) versus chromato-panning R1 for each library was evaluated based on non-overlapping 95\% CI's (corresponding to $\mathrm{p}<0.05)$. The good quality of the fits can be judged from the $\mathrm{R}^{2}$-value (explained variance).

An overall judgment of statistical difference for the three libraries was based on a paired t-test, comparing tube panning R1 with chromato-panning R1.

\section{Authors' contributions}

WN performed all practical experimental work. FP designed and produced the cryogel columns. IG participated in the experimental design. HP performed the statistical analysis. HD and BM supervised the work. The final manuscript was read and accepted by all co-authors.

\section{Acknowledgements}

This work was financially supported by Protista Biotechnology AB (Lund, Sweden). W.N. expresses his gratitude for the fellowship provided by the Swedish Institute. Dr. S. Deroo (Laboratory of Retrovirology, Luxembourg) is acknowledged for the amplification of the L6 and LI 5 phage peptide libraries.

\section{References}

I. Smith GP: Filamentous fusion phage: Novel expression vectors that display cloned antigens on the virion surface. Science 1985, 228:1315-1316.

2. Adda CG, Anders RF, Tilley L, Foley M: Random sequence libraries displayed on phage: Identification of biologically important molecules. Comb Chem High Throughput Screen 2002, 5: I-I4.

3. Byeon $\mathrm{W}-\mathrm{H}, \mathrm{W}$ eisblum $\mathrm{B}$ : Affinity adsorbent based on combinatorial phage display peptides that bind $\alpha$-cobratoxin. J Chromatogr B 2004, 805:36 |-363.

4. Huang PY, Baumbach GA, Dadd CA, Buettner JA, Masecar BL, Hentsch M, Hammond DJ, Carbonell RG: Affinity purification of von Willebrand factor using ligands derived from peptide libraries. Bioorg Medicin Chem 1996, 4:699-708.

5. Brix-Jensen L, Riise E, Nielsen LK, Dziegel M, Fugger L, Engberg J: Efficient purification of unique antibodies using peptide affinitymatrix columns. J of Immunolog Methods 2004, 284:45-54.

6. $Y u H-Q$, Dong $X-Y$, Sun $Y$ : Affinity chromatography of insulin with a heptapeptide ligand selected from phage display library. Chromatographia 2004, 60:379-383.

7. Noppe W, Vanhoorelbeke K, Yu Galaev I, Mattiasson B, Deckmyn H: $A$ probe for capture and $\mathrm{Fe}^{3+}$-induced conformational change of lactoferrin selected from phage displayed peptide libraries. J Dairy Sci 2004, 87( I 0):3247-3255.

8. Sato AK, Sexton DJ, Morganelli LA, Cohen RH, Wu QL, Conley GP, Streltsova Z, Lee SW, Devlin M, DeOliviera DB, Enright J, Kent RB, Wescott CR, Ransohoff TC, Ley AC, Ladner RC: Development of mammalian serum albumin affinity purification media by peptide phage display. Biotechnol Prog 2002, 1 8: $182-192$.

9. Kelley BD, Tannatt M, Magnusson R, Hagelberg S, Booth J: Development and validation of an affinity chromatography step using a peptide ligand for cGMP production of factor VIII. Biotechnol Bioeng 2004, 87:400-4I2.

10. Hunt AC, Williams SC, Davis PJ, Badley RA: Epitope mapping of bovine alpha-lactalbumin using a random phage display peptide library. Biochem Soc Transactions 1997, 25:160S.

II. Kehoe JW, Kay BK: Filamentous phage display in the new millenium. Chem Rev 2005, 105:4056-4072.

12. Paschke M: Phage systems and their applications. Appl Microbiol Biotechnol 2006, 70:2-II.

13. Szardenings $M$ : Phage display of random peptide libraries: Applications, limits, and potential. J Recept Signal Transduct Res 2003, 23:307-349.

14. Arap MA: Phage display technology - Applications and innovations. Gen Mol Biol 2005, I:I-9.

15. Mersich $C$, Jungbauer A: Generation of bioactive peptides by biological libraries. J Chromatogr B 2008, 861:160-I70.

16. Petrenko VA: Evolution of phage display: from bioactive peptides to bioselective nanomaterials. Expert Opin Drug Deliv 2008, 5:I-I2.

17. Arvidsson P, Plieva FM, Savina IN, Lozinsky VI, Fexby S, Bülow L, Yu Galaev I, Mattiasson B: Chromatography of microbial cells using continuous super-macroporous affinity and ion-exchange columns. J Chromatogr A 2002, 977:27-38.

18. Kumar A, Plieva FM, Yu Galaev I, Mattiasson B: Affinity fractionation of lymphocytes using a monolithic cryogel. J Immunol Methods 2003, 283:185-194. 
19. Dainiak MB, Plieva FM, Yu Galaev I, Hatti-Kaul R, Mattiasson B: Cell chromatography: Separation of different microbial cells using IMAC supermacroporous monolithic columns. Biotechnol Prog 2005, $21: 644-649$.

20. Dainiak MB, Kumar A, Yu Galaev I, Mattiasson B: Detachment of affinity-captured bioparticles by elastic deformation of a macroporous hydrogel. Proc Nat Acad Sci USA 2006, 103:849-854.

21. Lozinsky VI, Yu Galaev I, Plieva FM, Savina IN, Jungvid H, Mattiasson B: Polymeric cryogels as promising materials of biotechnological interest. Trends in Biotechnology 2003, 21 :445-45I.

22. Plieva FM, Yu Galaev I, Mattiasson B: Macroporous gels prepared at subzero temperatures as novel materials for chromatography of particulate-containing fluids and cell culture applications. J Sep Sci 2007, 30:1657-1671.

23. Plieva FM, Huiting $X, Y u$ Galaev I, Bergenståhl B, Mattiasson B: Macroporous elastic polyacrylamide gels prepared at subzero temperatures: control of porous structure. J Mater Chem 2006, 16:4065-4073.

24. Plieva FM, Karlsson M, Aguilar M-R, Gomez D, Mikhalovsky S, Yu Galaev I: Pore structure in supermacroporous polyacrylamide based cryogels. Soft Matter 2005, I:303-309.

25. Noppe W, Plieva FM, Yu Galaev I, Vanhoorelbeke K, Mattiasson B, Deckmyn H: Immobilised peptide displaying phages as affinity ligands: Purification of lactoferrin from defatted milk. J Chromatagr A 2006, I I 01:79-85.

26. Noppe W, Plieva FM, Vanhoorelbeke K, Deckmyn H, Tuncel M, Tuncel A, Yu Galaev I, Mattiasson B: Macroporous monolithic gels, cryogels, with immo-bilized phages from phage-display library as a new platform for fast development of affinity adsorbent capable of target capture from crude feeds. J Biotechnol 2007, | 3 |:293-299.

27. Plieva FM, Savina IN, Deraz S, Andersson J, Yu Galaev I, Mattiasson B: Characterization of supermacroporous monolith poly-acrylamide based matrices designed for chromatography of bioparticles. J Chromatogr B 2004, 807: I29-137.

28. Yu X, Owens GP, Gilden DH: Rapid and efficient identification of epitopes/mimotopes from random peptide libraries. J Immunol Methods 2006, 3 1 6:67-74.

29. Lunder M, Bratkovič T, Kreft S, Štrukelj B: Peptide inhibitor of pancreatic lipase selected by phage display using different elution strategies. J Lipid Res 2005, 46:1512-1516

30. Vanhercke T, Ampe C, Tirry L, Denolf P: Rescue and In Situ Selection and Evaluation (RISE): A method for high-throughput panning of phage display libraries. J of Biomolec Screen 2005, 10:108-117.

Publish with Bio Med Central and every scientist can read your work free of charge

"BioMed Central will be the most significant development for disseminating the results of biomedical research in our lifetime. "

Sir Paul Nurse, Cancer Research UK

Your research papers will be:

- available free of charge to the entire biomedical community

- peer reviewed and published immediately upon acceptance

- cited in PubMed and archived on PubMed Central

- yours - you keep the copyright
BioMedcentral 